NASA/TM-2002-211578

Fast Three-Dimensional Method of Modeling Atomic Oxygen Undercutting of Protected Polymers

Aaron Snyder and Bruce A. Banks

Glenn Research Center, Cleveland, Ohio 
Since its founding, NASA has been dedicated to the advancement of aeronautics and space science. The NASA Scientific and Technical Information (STI) Program Office plays a key part in helping NASA maintain this important role.

The NASA STI Program Office is operated by Langley Research Center, the Lead Center for NASA's scientific and technical information. The NASA STI Program Office provides access to the NASA STI Database, the largest collection of aeronautical and space science STI in the world. The Program Office is also NASA's institutional mechanism for disseminating the results of its research and development activities. These results are published by NASA in the NASA STI Report Series, which includes the following report types:

- $\quad$ TECHNICAL PUBLICATION. Reports of completed research or a major significant phase of research that present the results of NASA programs and include extensive data or theoretical analysis. Includes compilations of significant scientific and technical data and information deemed to be of continuing reference value. NASA's counterpart of peerreviewed formal professional papers but has less stringent limitations on manuscript length and extent of graphic presentations.

- TECHNICAL MEMORANDUM. Scientific and technical findings that are preliminary or of specialized interest, e.g., quick release reports, working papers, and bibliographies that contain minimal annotation. Does not contain extensive analysis.

- CONTRACTOR REPORT. Scientific and technical findings by NASA-sponsored contractors and grantees.
- CONFERENCE PUBLICATION. Collected papers from scientific and technical conferences, symposia, seminars, or other meetings sponsored or cosponsored by NASA.

- SPECIAL PUBLICATION. Scientific, technical, or historical information from NASA programs, projects, and missions, often concerned with subjects having substantial public interest.

- TECHNICAL TRANSLATION. Englishlanguage translations of foreign scientific and technical material pertinent to NASA's mission.

Specialized services that complement the STI Program Office's diverse offerings include creating custom thesauri, building customized data bases, organizing and publishing research results ... even providing videos.

For more information about the NASA STI Program Office, see the following:

- Access the NASA STI Program Home Page at http://www.sti.nasa.gov

- E-mail your question via the Internet to help@sti.nasa.gov

- Fax your question to the NASA Access Help Desk at 301-621-0134

- Telephone the NASA Access Help Desk at 301-621-0390

- Write to:

NASA Access Help Desk

NASA Center for AeroSpace Information 7121 Standard Drive

Hanover, MD 21076 
NASA/TM-2002-211578

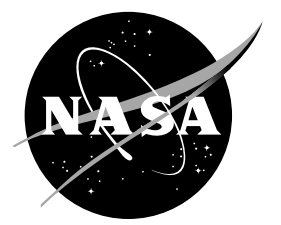

\section{Fast Three-Dimensional Method of Modeling Atomic Oxygen Undercutting of Protected Polymers}

Aaron Snyder and Bruce A. Banks

Glenn Research Center, Cleveland, Ohio

Prepared for the

Sixth International Conference on Protection of Materials and Structures From Space Environment cosponsored by the ITL, UTIAS, MMO, AFOSR/NL, CRESTech, EMS Technologies, and MDRobotics Toronto, Canada, May 1-3, 2002

National Aeronautics and Space Administration

Glenn Research Center 


\section{Acknowledgments}

The authors would like to thank Edward Sechkar for his contributions to the figures.

This report is a formal draft or working paper, intended to solicit comments and ideas from a technical peer group.

This report is a preprint of a paper intended for presentation at a conference. Because of changes that may be made before formal publication, this preprint is made available with the understanding that it will not be cited or reproduced without the permission of the author.

Trade names or manufacturers' names are used in this report for identification only. This usage does not constitute an official endorsement, either expressed or implied, by the National Aeronautics and Space Administration.

Available from

NASA Center for Aerospace Information 7121 Standard Drive

Hanover, MD 21076
National Technical Information Service 5285 Port Royal Road Springfield, VA 22100 


\title{
FAST THREE-DIMENSIONAL METHOD OF MODELING ATOMIC OXYGEN UNDERCUTTING OF PROTECTED POLYMERS
}

\author{
Aaron Snyder and Bruce A. Banks \\ National Aeronautics and Space Administration \\ Glenn Research Center \\ Cleveland, Ohio 44135
}

\begin{abstract}
A method is presented to model atomic oxygen erosion of protected polymers in low Earth orbit (LEO). Undercutting of protected polymers by atomic oxygen occurs in LEO due to the presence of scratch, crack or pin-window defects in the protective coatings. As a means of providing a better understanding of undercutting processes, a fast method of modeling atomic-oxygen undercutting of protected polymers has been developed. Current simulation methods often rely on computationally expensive raytracing procedures to track the surface-to-surface movement of individual "atoms". The method introduced in this paper replaces slow individual particle approaches by substituting a model that utilizes both a geometric configuration-factor technique, which governs the diffuse transport of atoms between surfaces, and an efficient telescoping series algorithm, which rapidly integrates the cumulative effects stemming from the numerous atomic oxygen events occurring at the surfaces of an undercut cavity. This new method facilitates the systematic study of three-dimensional undercutting by allowing rapid simulations to be made over a wide range of erosion parameters.
\end{abstract}

\section{INTRODUCTION}

Undercutting of protected polymers by atomic oxygen occurs in LEO due to the presence of scratch, crack or pin-window defects in the protective coatings. Methods to accurately model characteristics of undercutting beneath such defects exist, but due to the extremely complicated nature of the problem fall short of providing a complete representation of the undercutting process. For example, Monte-Carlo methods [1-2], when used in conjunction with ray-tracing procedures, produce remarkably faithful representations, yet are computationally exhaustive for small cell sizes, and thus often restricted to two spatial dimensions. Another deficiency for any method is the lack of knowledge as to what effective values should apply for atomic oxygen reaction and recombination rates at polymer and protective coating surfaces. Such lack of knowledge complicates correlation between in-space and ground based results. 
Proper correlation between ground-based systems and flight results are required for meaningful durability studies. A means of establishing such a correlation is the use of computer codes to simulate ground-based and in-space environments. To advance modeling of three-dimensional undercutting erosion yet minimize computational requirements, a procedure has been developed to provide fast and accurate simulations for a wide variety of conditions. This method shortcuts many computational bottlenecks and avoids lengthy ray tracing techniques by applying geometric configuration factors to determine the exchange of atoms between cavity surfaces, which in turn are approximated by simple geometric shapes.

The primary goal was to construct a procedure that provides reasonably accurate predictions and serves as a guide for the design of more complex codes. Simple geometries that are easily parameterized were selected. To limit the scope, individual geometries were chosen that exhibit qualities peculiar to directed beam undercutting resulting from a fixed ram direction. Therefore the geometric models used in this paper do not apply to simulation of arbitrary three-dimensional cavities, but are restricted to modeling classes of cavities that exhibit symmetry about an axis or a plane.

\section{GEOMETRIC MODEL}

As mentioned above, the code models three-dimensional undercut cavities by using a few prescribed geometries to serve as representative shapes for some of the more simple cavities observed from in-space undercutting below pin-window defects. In the model, undercutting occurs directly below a defect present in the upper protective coating of the film. With a double-coated film, a lower protective coating also exists. The protective coating is assumed to be infinitely thin. It is convenient and reasonable to use circular disks to represent the pin-window defects. Consistent with this simple defect shape, all model-geometry cavity cross sections in planes parallel to the polymer film are circular. In the present code, four specific geometric classifications exist. These four geometries are: (1) normal cylinder, (2) normal-truncated cone, (3) obliquecylinder, and (4) oblique-truncated cone. Each of these individual models was chosen to capture a specific set of features characteristic of the posthole-type erosion pattern arising from undercutting due to directed beam atomic oxygen. The degree of obliqueness of model (3) or model (4) is determined by the angle that the ram direction deviates from the film's surface-normal direction. The conical geometries allow for modeling of converging and diverging undercut cavities.

An equation for volume that is valid for the above geometric models is given by the following equation:

$$
V=\frac{\pi}{3} h\left(r_{1}^{2}+r_{1} r_{2}+r_{2}^{2}\right)
$$

where $r_{1}$ and $r_{2}$ are the upper and lower circular disk radii (see Figure 1), which are equal in the case of a cylindrical model. In order to provide a reasonable characterization, the radial and vertical dimensions of the model cavity must evolve 
synchronously with cavity volume in a suitable fashion. To automate the process and provide a degree of control in specifying model geometries, the radial coordinate, $r_{1}$, is chosen to be a simple function of the cavity height, $h$, for $h<h_{\mathrm{k}}$, where $h_{\mathrm{k}}$ is the polymer-film thickness. This function is given as follows:

$$
r_{1}=r_{d e f}+a h, \quad h<h_{k}
$$

For cylindrical geometries the radius is initially equal to the defect radius, $r_{d e f}$, and increases linearly with cavity height for $h<h_{\mathrm{k}}$. In the case of conical geometries an additional parameter, $b$, is introduced to relate the radii of the circular disks. Equation (2) is again used to specify $r_{1}$, and then $r_{2}$ is put in terms of $r_{1}$ as given by the following relation:

$$
r_{2}=r_{1}+b h, \quad h \leq h_{k}
$$

As the value of the parameter $b$ is negative, zero, or positive, the conical section is converging, cylindrical, or diverging, respectively. Since the volumes of these models are known functions of the radius and height, the cavity height can be solved in terms of the volume. The cavity's height, $h$, cannot exceed the polymer-film thickness, $h_{\mathrm{k}}$. The protective-coating thickness (typically 0.13 micron) is ignored. In this manner the cavity geometry is specified once the cavity volume is known. The parameters $a$ and $b$ control the cavity aspect ratio and cavity wall slope, respectively. As mentioned above, the degree of variation in the ram direction from normal determines the obliqueness of the model.

\section{PHYSICAL MODEL}

The present model assumes that non-reacting atomic-oxygen atoms reflect off surfaces diffusely, and consequently their movements between surfaces can be treated mathematically like diffuse radiation exchange between surfaces. The fraction of uniform diffuse radiation leaving one surface that reaches another is equivalent to the configuration factor between two surfaces, because it depends solely on the geometric orientation of the surfaces with respect to one another [3]. The geometric dependence of configuration factors can be used to derive algebraic relationships between factors. One pair of configuration factors exists for each pair of finite surfaces. A reciprocity relationship exists for the factors between two finite surfaces. It can be expressed by the following formula:

$$
A_{i} F_{i-j}=A_{j} F_{j-i},
$$

where 


$$
F_{j-i}=\frac{1}{A_{j}} \int_{A_{i}} \int_{A_{j}} \frac{\cos \theta_{i} \cos \theta_{j}}{\pi S^{2}} d A_{j} d A_{i}
$$

is the configuration factor from area $A_{j}$ to area $A_{i}$. The angles $\theta_{i}$ and $\theta_{j}$ are the angles between the line segment $S$, connecting the differential areas $d A_{i}$ and $d A_{j}$, and surface normals $\boldsymbol{n}_{i}$ and $\boldsymbol{n}_{j}$, respectively. To complete the general relations among configuration factors needed here, a conservation relation stating that the sum of fractions of emission leaving a surface and arriving at other surfaces of an enclosure (including the emitting surface) must sum to unity is expressed by equation (6). With the emitting surface denoted by the subscript index $j$ and the $N$ receiving surfaces of the enclosure identified by the running subscript index $i$, then the sum of configuration factors can be written compactly as:

$$
\sum_{i}^{N} F_{j-i}=1
$$

Given the above set of relationships, a complete set of configuration factors can be derived for an enclosed system starting from a relatively small initial subset, which for the geometries used here can be obtained from the existing literature on configuration factors [3]. An oblique truncated cone (converging downward from the defect surface) is shown in Figure 1. This geometry is one of the simple cavity geometries used here for thin film modeling. The upper surface of the enclosure is comprised of a central disk that represents the defect, and a circular annulus that represents that portion of the coating from which the substrate has been removed by undercutting. These two areas are denoted as area 1 and area 2, respectively. Connecting the upper and lower disks is the lateral wall area denoted as area 3. The lower disk is denoted as area 4 . Assuming $F_{4-1}$ and $F_{4-(1+2)}$ are either known by catalogued formula or calculated directly using equation (5), where the summed subscripts in the last factor indicate that the corresponding surface is a composite surface, then the complete set of factors for the enclosure is found by simple algebra. A list of this set of configuration factors and their origin are given in Table 1.

\section{COMPUTATIONAL MODEL}

The first step in arriving at a computational model is to provide an algorithm to determine the fraction of atoms arriving at a given surface after surviving an arbitrary number of bounces within the enclosure. Let $f_{i}^{0}$ be the fraction of atoms arriving directly through the defect that reach the $i^{\text {th }}$ surface without reflecting off a surface, and let $q_{i}^{n}$ be the probability that an atom arriving at the $i^{\text {th }}$ surface after $n$ previous cavity bounces will not react, recombine, or exit during the next surface collision, but reflect again. The fraction of atoms surviving one reflection is $q_{i}^{0} f_{i}^{0}$. Thus, by summing over 
all reflecting surfaces $j=1,2,3 \ldots N$ and employing the configuration factor, the fraction of atoms reaching the $i^{\text {th }}$ surface after one bounce is given by the following sum:

$$
f_{i}^{1}=\sum_{j}^{N} F_{j-i} q_{j}^{0} f_{j}^{0}
$$

Although the configuration factors must be recalculated as the cavity grows, they are held stationary over a given time-step interval. By telescoping from the first bounce, it can be shown that the fraction, $f_{i}^{n}$, of initial atoms entering the cavity during a given time-step interval that reach the $i^{\text {th }}$ surface after $n$ bounces is given by the following summation over the $N$ surfaces:

$$
f_{i}^{n}=\sum_{j}^{N} F_{j-i} q_{j}^{n-1} f_{j}^{n-1}, \quad n=1,2,3, \ldots
$$

The fraction of atoms recombining at a polymer surface, $f_{p}$, is found by summing (over the total number of impacts in a time step) the product of the fraction of atoms arriving at the surface times the probability $P_{r}^{n}$ of reaction, which in general changes between surface impacts. On average, energy is lost following a collision, and this loss is generally reflected in the code by selecting a lower reaction probability for the next impact. For convenience, consider the set of all polymer surfaces as being one surface denoted by the subscript $p$. Then the net fraction of atomic-oxygen atoms reacting at the polymer to cause erosion during a time step consisting of $N B$ bounces is given by the following expression:

$$
f_{n e t}^{N B}=\sum_{n=1}^{N B} P_{r}^{n-1} \sum_{j}^{N} F_{j-p} q_{j}^{n-1} f_{j}^{n-1} .
$$

The total number of atoms reacting is given by the product of the net fraction of atoms reacting and the total atoms entered, which itself is given by multiplying the atom fluence, $\Delta F$, during a time-step interval by the defect area, $A_{d e f}$. Continuing in this fashion, the product of the total number of atoms reacting and the erosion yield, $E$, (volume/atom) equals the amount of volume erosion, $\Delta V$, obtained during a time step, which is given by the following:

$$
\Delta V=f_{\text {net }}^{N B} \Delta F A_{\text {def }} E .
$$

The final undercut volume, $V$, is obtained by computing a series of $\Delta V$ volumes.

In preparation for discussing results, it is convenient to define the volume erosion gain, $G$, as the ratio of the volume of undercutting erosion below a defect site to the volume of erosion obtained on the surface of an unprotected "smooth-witness" 
sample, which had been exposed to the same number of atoms that entered the defect. In terms of simulation parameters, the above gain can be determined by dividing the average of the incremental $f_{n e t}^{N B}$ covering $N_{s}$ time steps by the initial reaction probability, $P_{r}^{0}$, and is given by

$$
G=\frac{\sum f_{n e t}^{N B}}{P_{r}^{0} N_{s}} .
$$

The "instantaneous" gain, $G^{\prime}$, corresponding to the gain for a single time-step interval is given by

$$
G^{\prime}=f_{n e t}^{N B} / P_{r}^{0},
$$

and provides a normalized erosion rate useful for comparison purposes. When $G^{\prime}$ equals one, the rate of undercutting erosion equals the rate of erosion of an unprotected smooth sample of area $A_{d e f}$ exposed to the same atom flux.

\section{RESULTS AND DISCUSSION}

Values of the erosion parameters representative of the LEO environment were used in simulations. These nominal values along with other code parameters are listed in Table 2. Any variation from these nominal values is noted in the text as the case occurs. Similar to ground-based experiments, simulated fluence is an effective fluence, equivalent to the atoms per unit area in LEO that would produce the same volume erosion. The in-space erosion yield $E$ for Kapton ${ }^{\circledR}$ representative of LEO is $3 \times 10^{-24} \mathrm{~cm}^{3} /$ atom based on atomic oxygen energy of $4.5 \mathrm{eV}$. It is emphasized that the tabulated entry for atomic-oxygen fluence is scaled by polymer-film thickness. Thus, normalized fluence-per-time-step-interval is listed as $2 \times 10^{22}$ atoms $/ \mathrm{cm}^{2}$ per $\mathrm{cm}$ of film thickness, giving a non-scaled cumulative fluence over 100 time steps, for example, of $5 \times 10^{21}$ atoms $/ \mathrm{cm}^{2}$ for a $0.0025 \mathrm{~cm}$ thickness film. In this fashion, having normalized the erosion rate by film thickness, the results in this paper hold for any film thickness.

To give an example of effects obtained by changing cavity shape, results are given comparing data for the normal-cylinder cavity model with data for the converging and diverging normal-cone cavity models. For the conical geometries, the final wall angle converges or diverges (downward from the defect) by 7.1 degrees from axial. For these three geometric models, the variation of normalized erosion rate $G^{\prime}$ versus fractional fluence is presented in Figure 2. It is readily seen in Figure 2 that whereas each curve is distinguished by the location of a steep dip, the characteristic shape of the curves remains the same for the different geometries. The dip in a curve coincides with the cavity reaching the lower protective coating. The reason that the dip occurs at a lower fluence for a converging cavity is that its volume grows more slowly with cavity height than the other cases, causing it to reach the lower coating first. For the same 
reason, the cavity of the cylindrical model reaches the lower coating before the cavity of the diverging-cone model.

Two of the most important parameters influencing undercutting erosion are the defect size $r_{\text {def }}$ and reaction probability $P_{r}^{0}$. To identify any gross effects observed with changes in these two parameters, the variation of final erosion gain, $G$, as a function of $r_{\text {def }}$ is shown in Figure 3 for various values of $P_{r}^{0}$ using the normal-cylinder geometry. For this data, $r_{\text {def }}$ ranges from $0.2 h_{\mathrm{k}}$ to $0.001 h_{\mathrm{k}}$. For a given $P_{r}^{0}, G$ increases rapidly with decreasing $r_{\text {def }}$ until, at a value of $r_{\text {def }}$ approximately equal to $0.1 h_{\mathrm{k}}$, little increase in $G$ is observed. Gains for the largest defect size, $r_{\text {def }}=0.2 h_{\mathrm{k}}$, are close to one, while gains for the smallest defect size, $r_{\text {def }}=0.001 h_{\mathrm{k}}$, are about $75 \%$ greater because of enhanced trapping of the atomic oxygen. It is seen that variations of plus or minus $20 \%$ from the nominal reaction probability $\left(P_{r}^{0}=0.11\right.$ ) produce respective changes in $G$ of approximately $-2.1 \%$ and $2.2 \%$ for the smallest defects and $-0.6 \%$ and $1.5 \%$ for the largest defects.

As a final example, a comparison of erosion rates is presented for singlecoated and double-coated Kapton ${ }^{\circledR}$ films. To simulate the effect of having no lower protective coating, the recombination probability is set equal to one at the lower film surface. In Figure 4 curves of the erosion rate, $G^{\prime}$, as a function of fractional fluence are shown for single-coated and double-coated Kapton ${ }^{\circledR}$ film using the normal-cylinder model. As expected, the curves are identical until the bottom surface is reached. In the double-coated polymer case, the presence of the lower coating results in additional erosion, beyond that obtained in the single-coated case, due to reflected atoms.

\section{SUMMARY}

A new method to simulate three-dimensional undercutting below pin-window defects in protected polymer thin films has been constructed. This method is very fast. To minimize computational requirements, it uses a geometric configuration-factor technique to govern the exchange of atoms between surfaces. The model assumes that non-reacting, non-recombining atoms reflect diffusely off surfaces. The basic equations to derive the view factors are given. In addition, a table listing the sequence of steps to derive a full set of configuration factors is provided for a representative case. A set of simple geometric shapes is used to model undercut cavities. A given geometric shape is selected based on its suitability to faithfully model particular qualities. These qualities belong to a small set of cavity characteristics, which include the cavity aspect ratio, cavity obliqueness to the film surface due to ram angle, and cavity-wall divergence. The equations relating the amount of volume erosion and the rate of volume erosion to the atomic-oxygen fluence are presented. Using a suitable set of simple geometries as models, rapid simulations can be obtained over a wide range of parameter space. Examples are given that illustrate typical results that may be obtained using the associated computer code. 


\section{TABLES}

Table 1. List of Configuration Factors Associated with the Geometry Illustrated in Figure 1 and Their Origin

\begin{tabular}{|c|c|}
\hline Configuration Factor & Origin of Configuration Factor \\
\hline$F_{4-1}$ & Known \\
\hline$F_{4-(1+2)}$ & Known \\
\hline$F_{4-2}=F_{4-(1+2)}-F_{4-1}$ & Prom definition of $F_{4-(1+2)}=F_{4-1}+F_{4-2}$ \\
\hline$F_{1-1}=F_{2-2}=F_{4-4}=0$ & Planar Areas, Equation (5) \\
\hline$F_{1-2}=F_{2-1}=0$ & Area 1 and area 2 in same plane, equation (5) \\
\hline$F_{1-4}=A_{4} F_{4-1} / A_{1}$ & Reciprocity, equation (4) \\
\hline$F_{2-4}=A_{4} F_{4-2} / A_{2}$ & Reciprocity, equation (4) \\
\hline$F_{1-3}=1-F_{1-4}$ & Conservation of atoms from area 1, equation (6) \\
\hline$F_{2-3}=1-F_{2-4}$, & Conservation of atoms from area 2, equation (6) \\
\hline$F_{4-3}=1-F_{4-1}-F_{4-2}$ & Conservation of atoms from area 4, equation (6) \\
\hline$F_{3-1}=A_{1} F_{1-3} / A_{3}$ & Reciprocity, equation (4) \\
\hline$F_{3-2}=A_{2} F_{2-3} / A_{3}$ & Reciprocity, equation (4) \\
\hline$F_{3-4}=A_{4} F_{4-3} / A_{3}$ & Reciprocity, equation (4) \\
\hline$F_{3-3}=1-F_{3-1}-F_{3-2}-F_{3-4}$ & Conservation of atoms from area 3, equation (6) \\
\hline
\end{tabular}

Table 2. Nominal Computational Model Parameters for LEO Atomic Oxygen Interaction with Kapton ${ }^{\circledR}$

\begin{tabular}{|c|c|}
\hline Atomic oxygen initial impact at polymer reaction probability & 0.11 \\
\hline Atomic oxygen asymptotic impact at polymer reaction probability & 0.001 \\
\hline Atomic oxygen impact at coating recombination probability & 0.13 \\
\hline Atomic oxygen impact at polymer recombination probability & 0.24 \\
\hline Fractional decrease in polymer reaction probability per impact & 0.368 \\
\hline Number of atom bounces per time step & 500 \\
\hline Atomic oxygen fluence (atoms $/ \mathrm{cm}^{2}$ ) per $\mathrm{cm}$ of film thickness per time step & $2 \times 10^{22}$ \\
\hline Number of erosion time steps & 100 \\
\hline Atomic oxygen fluence $\left(\right.$ atoms $/ \mathrm{cm}^{2}$ ) for $0.0025 \mathrm{~cm}$ thickness film & $5 \times 10^{21}$ \\
\hline Erosion yield $\left(\mathrm{cm}^{3} / \mathrm{AO}-\right.$ atom $)$ & $3 \times 10^{-24}$ \\
\hline Value of parameter $a$ in equation [2] & 0.0759 \\
\hline Values of parameter $b$ for $h=h_{\mathrm{k}}$ in equation [3] for conical geometry & $\pm r_{d e f}$ \\
\hline Protective coating defect size & $0.1 h_{\mathrm{k}}$ \\
\hline
\end{tabular}

\section{REFERENCES}

1. B. Banks, T. Stueber, S. Snyder, S. Rutledge, and M. Norris, Atomic Oxygen Erosion Phenomena, American Institute of Aeronautics Defense and Space Conference, Huntsville, Alabama, September 2325, 1997.

2. B. Banks, T. Stueber, and M. Norris, Monte-Carlo Computational Modeling of the Energy Dependence of Atomic Oxygen Undercutting of Protected Polymers, NASA TM-1998-207423, Fourth International Space Conference, ICPMSE-4, Toronto, Canada, April 23-24, 1998.

3. R. Siegel and J. Howell, "Thermal Radiation Heat Transfer," Second edition, Hemisphere Publishing Corporation, Washington D.C., 1981. 


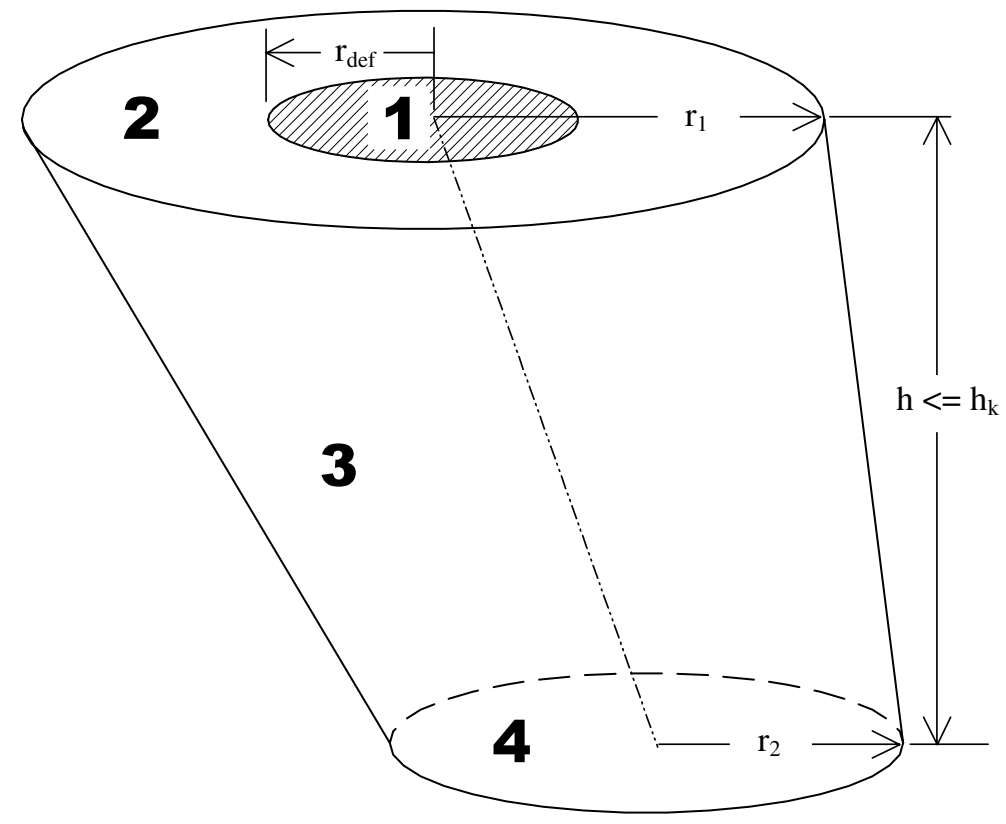

Figure 1.

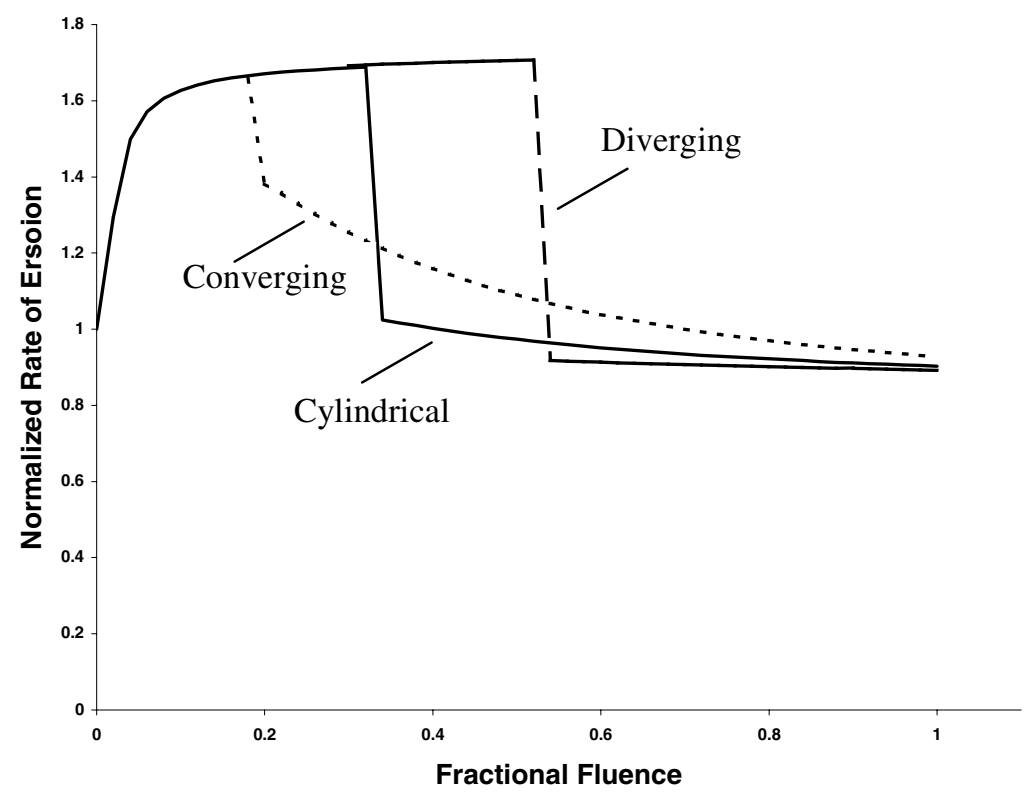

Figure 2. 


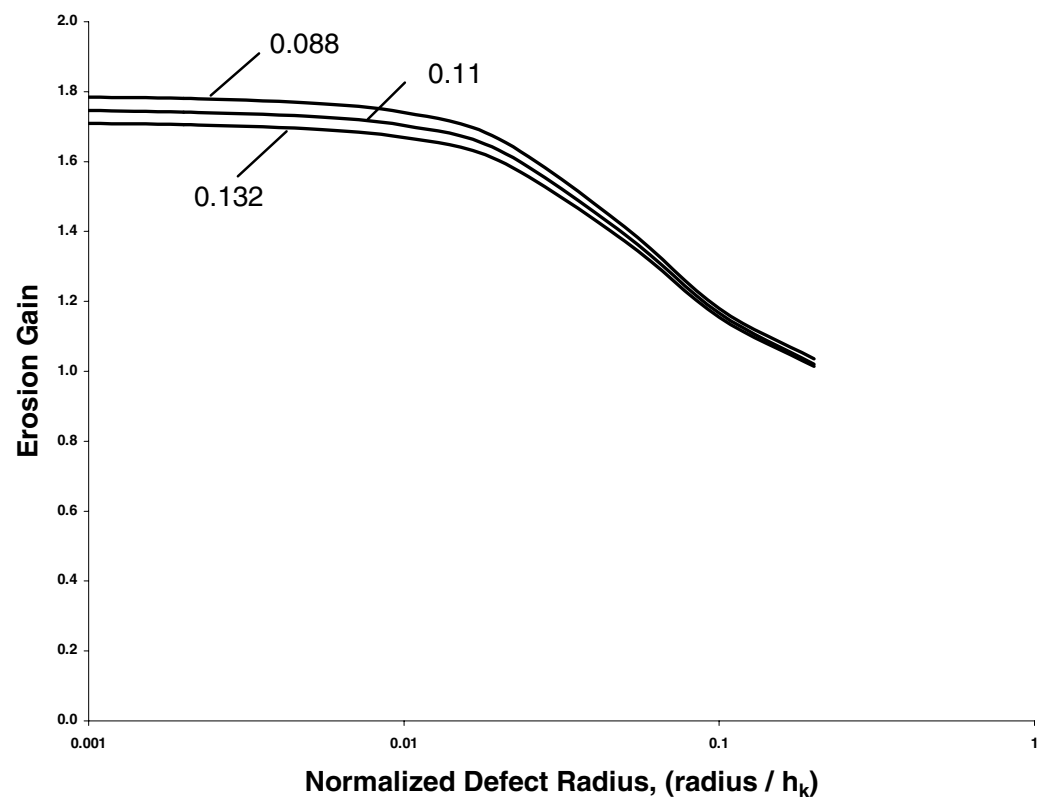

Figure 3.

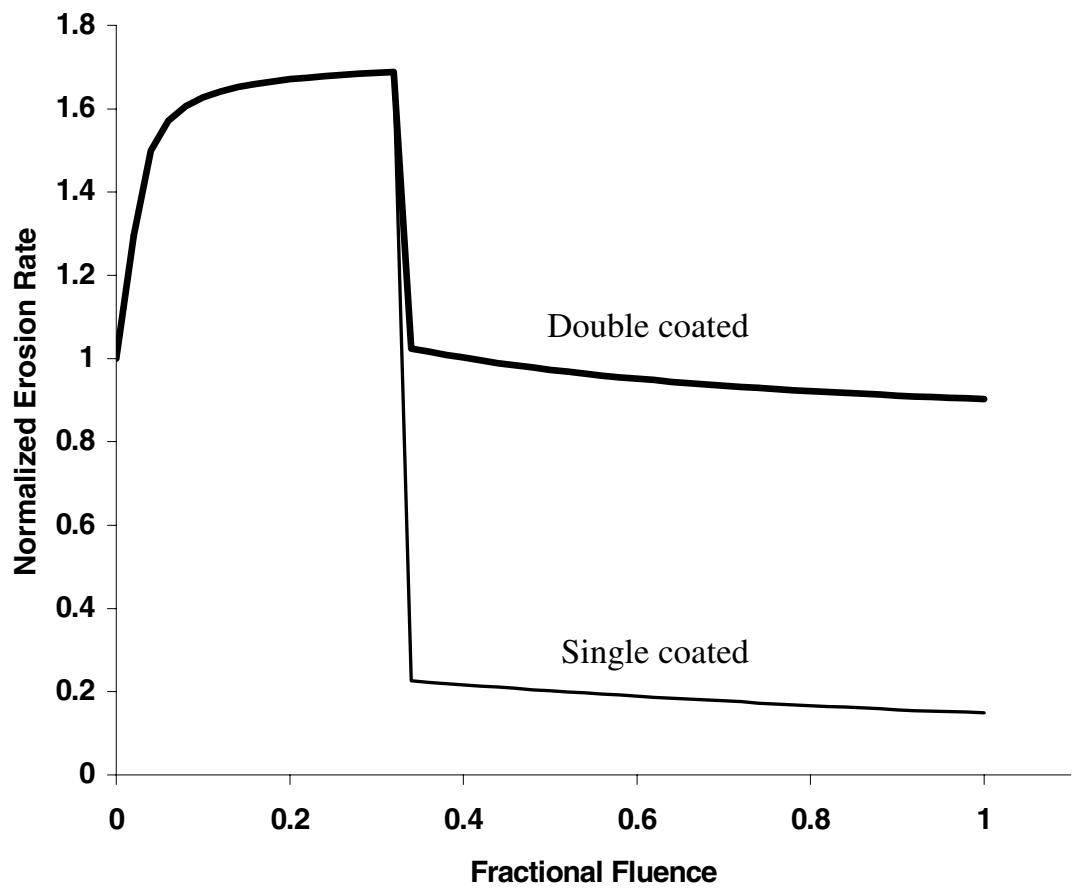

Figure 4. 
Public reporting burden for this collection of information is estimated to average 1 hour per response, including the time for reviewing instructions, searching existing data sources, gathering and maintaining the data needed, and completing and reviewing the collection of information. Send comments regarding this burden estimate or any other aspect of this collection of information, including suggestions for reducing this burden, to Washington Headquarters Services, Directorate for Information Operations and Reports, 1215 Jefferson Davis Highway, Suite 1204, Arlington, VA 22202-4302, and to the Office of Management and Budget, Paperwork Reduction Project (0704-0188), Washington, DC 20503.

\begin{tabular}{|l|l|l|}
\hline 1. AGENCY USE ONLY (Leave blank) & $\begin{array}{c}\text { 2. REPORT DATE } \\
\text { April } 2002\end{array}$ & $\begin{array}{r}\text { 3. REPORT TYPE AND DATES COVERED } \\
\text { Technical Memorandum }\end{array}$ \\
\hline
\end{tabular}

\section{TITLE AND SUBTITLE}

Fast Three-Dimensional Method of Modeling Atomic Oxygen Undercutting of Protected Polymers

\section{6. $\operatorname{AUTHOR(S)}$}

Aaron Snyder and Bruce A. Banks

\section{FUNDING NUMBERS}

WU-755-A4-06-00

\section{PERFORMING ORGANIZATION NAME(S) AND ADDRESS(ES)}

National Aeronautics and Space Administration

John H. Glenn Research Center at Lewis Field

Cleveland, Ohio 44135-3191
8. PERFORMING ORGANIZATION REPORT NUMBER

E-13363

\section{SPONSORING/MONITORING AGENCY NAME(S) AND ADDRESS(ES)}

National Aeronautics and Space Administration

Washington, DC 20546-0001

10. SPONSORING/MONITORING AGENCY REPORT NUMBER

NASA TM-2002-211578

\section{SUPPLEMENTARY NOTES}

Prepared for the Sixth International Conference on Protection of Materials and Structures From Space Environment cosponsored by the ITL, UTIAS, MMO, AFOSR/NL, CRESTech, EMS Technologies, and MDRobotics, Toronto, Canada, May 1-3, 2002. Responsible person, Aaron Snyder, organization code 5480, 216-433-5918.

12a. DISTRIBUTION/AVAILABILITY STATEMENT

12b. DISTRIBUTION CODE

Unclassified - Unlimited

Subject Category: 18

Distribution: Nonstandard

Available electronically at http://gltrs.grc.nasa.gov/GLTRS

This publication is available from the NASA Center for AeroSpace Information, 301-621-0390.

13. ABSTRACT (Maximum 200 words)

A method is presented to model atomic oxygen erosion of protected polymers in low Earth orbit (LEO). Undercutting of protected polymers by atomic oxygen occurs in LEO due to the presence of scratch, crack or pin-window defects in the protective coatings. As a means of providing a better understanding of undercutting processes, a fast method of modeling atomic-oxygen undercutting of protected polymers has been developed. Current simulation methods often rely on computationally expensive ray-tracing procedures to track the surface-to-surface movement of individual "atoms." The method introduced in this paper replaces slow individual particle approaches by substituting a model that utilizes both a geometric configuration-factor technique, which governs the diffuse transport of atoms between surfaces, and an efficient telescoping series algorithm, which rapidly integrates the cumulative effects stemming from the numerous atomic oxygen events occurring at the surfaces of an undercut cavity. This new method facilitates the systematic study of threedimensional undercutting by allowing rapid simulations to be made over a wide range of erosion parameters.

\section{SUBJECT TERMS}

Atmospheric effects; Low Earth orbit; Atomic oxygen; Erosion; Durability; Space environment

\begin{tabular}{|c|c|c|}
\hline $\begin{array}{c}\text { 17. SECURITY CLASSIFICATION } \\
\text { OF REPORT } \\
\text { Unclassified }\end{array}$ & $\begin{array}{c}\text { 18. SECURITY CLASSIFICATION } \\
\text { OF THIS PAGE } \\
\text { Unclassified }\end{array}$ & $\begin{array}{c}\text { 19. SECURITY CLASSIFICATION } \\
\text { OF ABSTRACT } \\
\text { Unclassified }\end{array}$ \\
\hline
\end{tabular}

